\title{
Improvement of a delayed swallowing reflex following treatment for advanced head and neck cancer
}

\author{
Akira Ohkoshi* ${ }^{*}$, Kengo Kato, Takenori Ogawa, Ayako Nakanome, Ryo Ishii and Yukio Katori
}

\begin{abstract}
Background: The latency of the swallowing reflex is an important factor causing dysphagia in head and neck cancer patients. Although there are many reports comparing voluntary swallowing function before and after treatment, few studies have focused on the latency of the swallowing reflex, which is a risk factor for pneumonia due to silent aspiration. The aim of this retrospective study was to clarify the changes in the latency of the swallowing reflex before and after treatment.
\end{abstract}

Methods: The latency of the swallowing reflex was quantified using the time from the injection of $1 \mathrm{ml}$ of distilled water into the pharynx through a nasal catheter to the onset of swallowing.

Results: The latency time of the swallowing reflex was significantly decreased 3 months after treatment compared to before treatment. A significant reduction was also observed in patients with pharyngeal cancer who underwent chemoradiation therapy.

Conclusions: This retrospective study showed that a delayed swallowing reflex improved with treatment in advanced head and neck cancer patients.

Trial registration: The Institutional Review Board of Tohoku University Hospital (Number 2014-1-274).

Keywords: Head and neck cancer, Swallowing disorder, Latency time of the swallowing reflex

\section{Background}

Advanced head and neck cancer and its treatment cause swallowing disorders that reduce patients' quality of life and decrease survival $[1,2]$. The mechanisms of dysphagia resulting from treatment of advanced head and neck cancer are various, such as reduced tongue base retraction, reduced laryngeal elevation, cricopharyngeal dysfunction, and a delayed swallowing reflex $[3,4]$. Of the various mechanisms, both a delayed swallowing reflex and reduced elevation of the larynx are reported to be independent risk factors for aspiration pneumonia in head and neck cancer patients [5]. A delayed swallowing

\footnotetext{
* Correspondence: ohkoshia@hotmail.com

Department of Otorhinolaryngology, Head and Neck Surgery, Tohoku University Graduate School of Medicine, 1-1 Seiryo-cho, Aoba-ku, Sendai 980-8575, Japan
}

(C) The Author(s). 2020 Open Access This article is licensed under a Creative Commons Attribution 4.0 International License, which permits use, sharing, adaptation, distribution and reproduction in any medium or format, as long as you give

appropriate credit to the original author(s) and the source, provide a link to the Creative Commons licence, and indicate if changes were made. The images or other third party material in this article are included in the article's Creative Commons licence, unless indicated otherwise in a credit line to the material. If material is not included in the article's Creative Commons licence and your intended use is not permitted by statutory regulation or exceeds the permitted use, you will need to obtain permission directly from the copyright holder. To view a copy of this licence, visit http://creativecommons.org/licenses/by/4.0/. cretions, which is also known to be a risk factor for pneumonia in older people [6]. Although there are many reports of voluntary swallowing examined by videofluorography, the gold standard method for evaluation of dysphagia, or by flexible videoendoscopy, first reported in 1988 by Langmore and colleagues, few studies have examined silent aspiration due to attenuation of the swallowing reflex in head and neck cancer patients [7, 8]. The latency time of the swallowing reflex can be measured easily by bolus injection of a small amount of distilled water into the pharynx through a nasal catheter [9]. Head and neck cancer treatment, including both surgery and chemoradiation may result in a delayed swallowing reflex $[10,11]$. Whereas direct invasion of tumor to the pharynx causes a delayed swallowing reflex, 
the disappearance of tumor with treatment may improve swallowing function [12, 13]. Although there are many reports comparing swallowing function before and after treatment, few studies have focused on the latency of the swallowing reflex $[14,15]$. Thus, a retrospective study of patients with advanced head and neck cancer was conducted to clarify the changes of the latency of the swallowing reflex from before to after treatment.

\section{Methods}

\section{Patient selection}

This retrospective study was performed in accordance with the Helsinki Declaration and approved by The Institutional Review Board of Tohoku University Hospital (Number 2014-1-274). All patients who received treatment, including surgery and radiation therapy with or without chemotherapy, for advanced head and neck cancer and whose latency of the swallowing reflex was assessed both before and 3 months after treatment at the Department of Otolaryngology-Head and Neck Surgery of Tohoku University Hospital between April 2014 and March 2019 were included. Patients who underwent total laryngectomy at the same time or had recurrence within 3 month after treatment were excluded. The assessments were done at 3 month after completion of adjuvant treatment in patients who received post-operative therapy. In this study, 116 patients have received treatment for advanced head and neck cancer with laryngeal preservation, of which 73 patients have assessed the latency of the swallowing reflex before treatment. Finally, 53 patients have received the assessment both before and after treatment. Assessment of the latency of the swallowing reflex was performed before flexible endoscopic evaluation of swallowing, which was performed as standard practice for all patients with advanced head and neck cancer after they provided their written, informed consent.

\section{Assessment of the latency of the swallowing reflex}

Individual latency time of the swallowing reflex was assessed before and 3 months after treatment. The swallowing reflex was induced by a bolus injection of $1 \mathrm{ml}$ of distilled water into the pharynx through an 8-Fr nasal catheter. Before injection, the catheter was positioned below the soft palate. The subjects were unaware of the actual injection. Swallowing was identified by visual observation of characteristic laryngeal movement. The latency of the swallowing reflex was quantified using the time from the injection to the onset of swallowing, and the average of 3 measurements was used in the analysis [16]. According to previous research, the latency time of the swallowing reflex is $1.2 \pm 0.1 \mathrm{~s}$ in healthy control subjects, $5.2 \pm 0.6 \mathrm{~s}$ in older people with dementia, and $12.5 \pm 3.0 \mathrm{~s}$ in older people with aspiration pneumonia
[17]. Because a previous study treated patients with a latency time less than $3 \mathrm{~s}$ as a low-risk group for pneumonia, patients with a latency time greater than $3 \mathrm{~s}$ were defined as having a delayed swallowing reflex in this study [9].

\section{Statistical analysis}

Differences were evaluated for significance using the paired $t$-test, Wilcoxon rank-sum test, or Fisher's exact test. Values are presented as means \pm SD.

\section{Results}

A total of 53 patients ( 37 men and 16 women) were enrolled in this study, with an age range of 18-82 (median 65) years. The characteristics of the patients are shown in Table 1. There were 28 patients with oral cancers and 25 with pharyngeal cancers, including 17 oropharyngeal and 8 hypopharyngeal cancers. Forty-four patients were clinical stage IV, and 9 patients were stage III. Twentythree patients underwent surgery, 22 patients received chemoradiation, 6 patients received both surgery and chemoradiation, and the other 2 patients received radiation without chemotherapy.

To evaluate whether the treatment of head and neck cancer changes the swallowing reflex, the latency time of the swallowing reflex was compared before and 3 months after treatment. The latency time of the swallowing reflex was significantly decreased at 3 months after treatment $(1.91 \pm 0.61 \mathrm{~s})$ compared to before treatment $(2.57 \pm 1.73 \mathrm{~s}$, $p=0.012$, paired $t$-test, Fig. 1a). The percentage of patients with a delayed swallowing reflex was also significantly decreased at 3 months after treatment $(3 / 53,5.6 \%)$ compared

Table 1 Patients' characteristics

\begin{tabular}{ll}
\hline Number of patients & 53 \\
\hline Age (y) (median) & $18-82(65)$ \\
Sex (male/female) & $37 / 16$ \\
Primary site & \\
Oral & 28 \\
Pharynx & 25 \\
Oropharynx & 17 \\
Hypopharynx & 8 \\
Clinical stage & \\
III & 9 \\
IV & 44 \\
Treatment & \\
Surgery & 23 \\
Chemoradiation & 22 \\
Surgery + Chemoradiation & 6 \\
Radiation & 2 \\
\hline
\end{tabular}


A

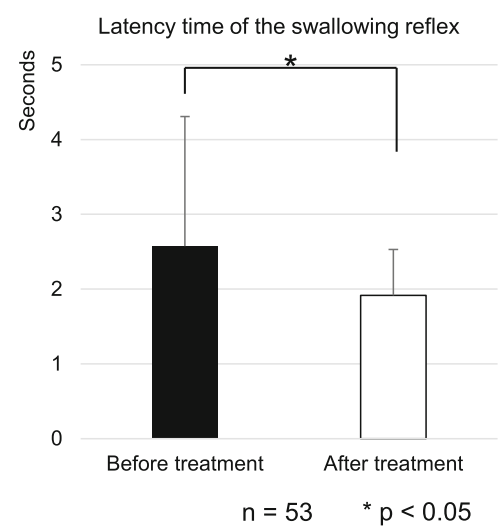

B

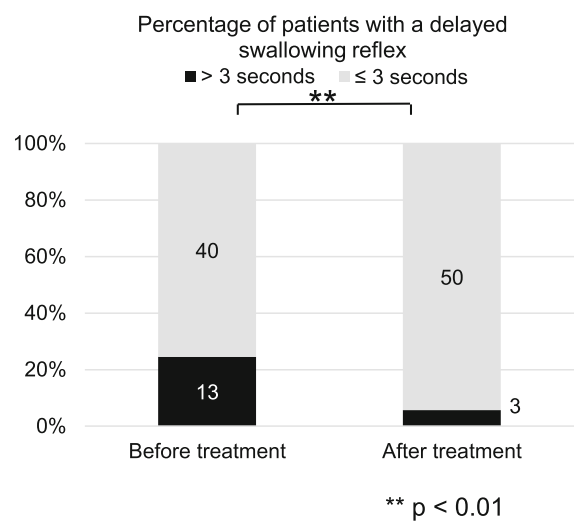

Fig. 1 Latency of the swallowing reflex before and 3 months after treatment. Asterisks indicate significant differences between before and after treatment. The error bars indicate standard deviation. a Comparison of the latency time of the swallowing reflex before and 3 months after treatment ( $n=53, p<0.05$, paired t-test). $\mathbf{b}$ Comparison of the percentage of patients with a delayed swallowing reflex before and 3 months after treatment $(p<0.01$, Fisher's exact test). Time over $3 \mathrm{~s}$ was defined as a delayed swallowing reflex

to before treatment $(13 / 53,24.5 \%, p=0.0073$, Fisher's exact test, Fig. 1b).

Next, in order to examine the difference among the sites of head and neck cancer, the 53 patients were divided into those with cancers of the oral cavity $(n=28)$ and the pharynx $(n=25)$, which was further subdivided into oropharynx $(n=17)$ and hypopharynx $(n=8)$. Whereas there was no significant difference between before and 3 months after treatment in patients with the cancers of the oral cavity $(2.24 \pm 1.27$ to $2.01 \pm 0.71 \mathrm{~s}$, $p=0.98$, Wilcoxon rank-sum test), a significant reduction of the latency time of the swallowing reflex was observed in patients with cancers of the pharynx $(2.89 \pm$
2.11 to $1.80 \pm 0.46 \mathrm{~s}, p=0.014$, Wilcoxon rank-sum test, Fig. 2a). No significant reduction of the latency time of the swallowing reflex was observed in patients with cancers of the oropharynx ( $3.02 \pm 2.48$ to $1.85 \pm 0.52 \mathrm{~s}$ ), but it was observed in those with cancers of the hypopharynx $(2.61 \pm 1.01$ to $1.88 \pm 0.23 \mathrm{~s}, p<0.05$, Wilcoxon ranksum test, Fig. 2a). On the other hand, the percentage of patients with a delayed swallowing reflex was not significantly changed in patients with cancers of the oral cavity $(6 / 28,21.4 \%$ to $3 / 28,10.7 \%, p=0.30$, Fisher's exact test), whereas a significant reduction was observed in patients with cancers of the pharynx $(7 / 25,28.0 \%$ to $0 / 28,0 \%$, $p=0.0096$, Fisher's exact test, Fig. 2b). However, no
A

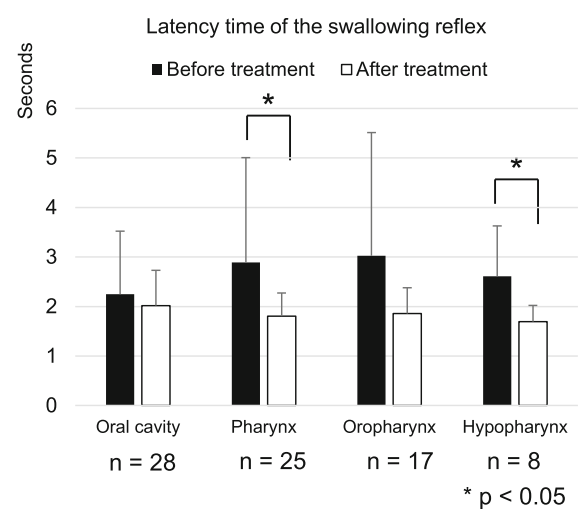

B

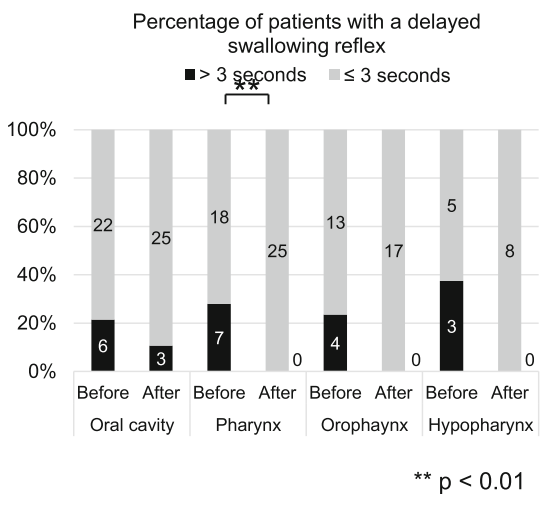

Fig. 2 Latency of the swallowing reflex before and 3 months after treatment among the sites of head and neck cancer. Asterisks indicate significant differences between before and after treatment. The error bars indicate standard deviation. a Comparison of the latency time of the swallowing reflex between before and 3 months after treatment in cancers of the oral cavity $(n=28)$, pharynx $(n=25, p<0.05$, Wilcoxon rank-sum test), oropharynx ( $n=17)$, and hypopharynx $(n=8, p<0.05$, Wilcoxon rank-sum test). $\mathbf{b}$ Comparison of the percentage of patients with a delayed swallowing reflex between before and 3 months after treatment in patients with cancers of the oral cavity, pharynx ( $p<0.01$, Fisher's exact test), oropharynx, and hypopharynx. Time over $3 \mathrm{~s}$ was defined as a delayed swallowing reflex 
significant reduction of the percentage of patients with a delayed swallowing reflex was observed in patients with cancers of the oropharynx or hypopharynx (Fig. 2b).

Next, in order to examine the difference among treatments, the patients were divided into those treated with surgery $(n=23)$ and those treated with chemoradiation $(n=22)$. Patients who underwent both surgery and chemoradiation $(n=6)$ and those who underwent radiation without chemotherapy $(n=2)$ were excluded because of their small numbers. Whereas there was no significant difference between before and 3 months after treatment in the patients who underwent surgery $(2.08 \pm 0.93$ to $2.10 \pm 0.72 \mathrm{~s}$, $p=0.68$, Wilcoxon rank-sum test), significant reduction of the latency time of the swallowing reflex was observed in the patients who underwent chemoradiation $(2.80 \pm 1.83$ to $1.76 \pm 0.45 \mathrm{~s}, p=0.025$, Wilcoxon rank-sum test, Fig. 3a). On the other hand, the percentage of patients with a delayed swallowing reflex was not significantly changed in the patients who underwent surgery $(4 / 23,17.3 \%$ to $3 / 23,13.0 \%, p=$ 1.00 , Fisher's exact test), whereas a significant reduction was observed in the patients who underwent chemoradiation $(5 / 22,22.7 \%$ to $0 / 22,0 \%, p=0.048$, Fisher's exact test, Fig. 3b).

\section{Discussion}

This study demonstrated that a delayed swallowing reflex improved after treatment in advanced head and neck cancer patients. A delayed swallowing reflex is known to be an independent risk factor for aspiration pneumonia in head and neck cancer patients [5]. Both invasion of the tumor into the pharynx and cancer treatment including surgery and chemoradiation are known to cause a delayed swallowing reflex due to decreased pharyngeal sensation [10-12]. Although there are many reports comparing swallowing function, such as laryngeal elevation or penetrationaspiration, before and after treatment, few studies have focused on the latency of the swallowing reflex. To the best of our knowledge, this is the first report showing significant improvement in the delayed swallowing reflex after treatment in head and neck cancer patients. Despite an increased rate of dysphagia in patients after treatment due to reduced tongue base retraction, reduced laryngeal elevation, cricopharyngeal dysfunction, and so on, some patients reported improved swallowing function [18, 19]. In addition to disappearance of tumor, the improvement of a delayed swallowing reflex shown in the present study may contribute to recovery from dysphagia in such cases. In the present study, improvement of a delayed swallowing reflex was observed only in patients with pharyngeal cancer or who received chemoradiation. Because most patients (22 of 25 patients) with pharyngeal cancer received chemoradiation, the difference between the two groups was considered to be small in the present study. Since chemoradiation for pharyngeal cancer causes various sensory disorders with mucositis, such as pharyngeal pain, xerostomia, and dysgeusia, the improvement of a delayed swallowing reflex shown in the present study may have some relationship with pharyngeal hypersensitivity following radiation pharyngitis $[20,21]$. On the other hand, no improvement of the swallowing reflex was observed in patients with oral cancer or those who underwent

\section{A}

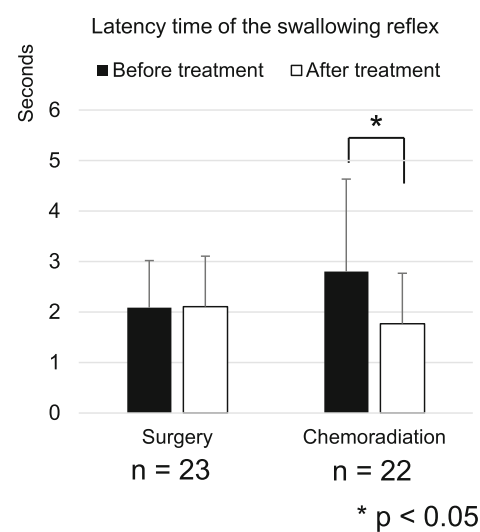

B

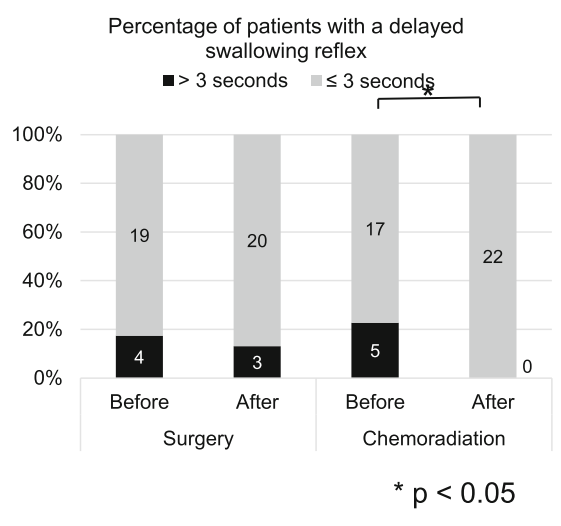

Fig. 3 Latency of the swallowing reflex before and 3 months after surgery or chemoradiation. Asterisks indicate significant differences between before and after treatment. The error bars indicate standard deviation. a Comparison of the latency time of the swallowing reflex between before and 3 months after surgery $(n=23)$ or chemoradiation $(n=22, p<0.05$, Wilcoxon rank-sum test). $\mathbf{b}$ Comparison of the percentage of patients with a delayed swallowing reflex between before and 3 months after surgery or chemoradiation ( $p<0.05$, Fisher's exact test). Time over $3 \mathrm{~s}$ was defined as a delayed swallowing reflex 
surgery in the present study. Because the swallowing reflex was induced by injection of water into the pharynx in the present study, oral cancer without direct invasion into the pharynx or surgery without manipulation of the pharynx was thought to have little effect on the swallowing reflex.

In contrast to the results of the present study, many previous reports have shown that chemoradiation causes a delay of the swallowing reflex [4, 5]. The contradiction can be explained by the fact that many previous reports examined voluntary swallowing, but the present study focused on spontaneous swallowing in which the subjects were unaware of the actual injection of distilled water into the pharynx. The spontaneous swallowing reflex is reported to mediated by substance $P$, which is also known to be upregulated by capsaicin $[6,9]$. Interestingly, radiation therapy is reported to induce an early increase in substance $P$ and produce an increased cough reflex [22]. However, substance $\mathrm{P}$ is also reported to decrease with longterm follow-up [23]. In the present study, the swallowing reflex was evaluated at only one point following treatment, 3 months after treatment; long-term follow-up might show the return of a delayed swallowing reflex.

The present study has several limitations. First, this retrospective study did not consider oral food intake or swallowing function other than the latency of the swallowing reflex. As in many other reports, despite the improvement of the delayed swallowing reflex, oral food intake of the patients in the present study did not improve after treatment (data not shown). This is thought to be because oral food intake is affected by many factors other than the latency of the swallowing reflex, such as prophylactic nutrition tube placement, xerostomia, and dysgeusia [24]. Second, the latency of the swallowing reflex was measured at only one point following treatment, 3 months after treatment, in the present study. Although pharyngeal mucositis and pain have ceased at this point, hypersensitivity of the pharynx can be present and affect the results. Third, this study had a small sample size, and only the data of patients who underwent testing both before and 3 months after treatment were included, so that there was some selection bias. Moreover, this study included small numbers of pharyngeal cancer patients who underwent surgery. Surgery of the tongue base, which is well known to cause dysphagia, could have affected the results of the present study [25]. Despite these limitations, this study provides valuable information about the latency of the swallowing reflex before and after treatment in head and neck cancer patients. The result will be helpful for better management of patients with swallowing disorders, and further prospective evaluation of large numbers of patients at later time points after treatment may be of greater benefit.

\section{Conclusion}

This retrospective study showed that a delayed swallowing reflex improved after treatment in advanced head and neck cancer patients.

\begin{abstract}
Acknowledgements
Not applicable.

Authors' contributions

$\mathrm{AO}$ designed the study and wrote the initial draft of the manuscript. KK designed the study and assisted in the preparation of the manuscript. TO and AN contributed to analysis and interpretation of the data. RI and YK contributed to data collection and interpretation, and critically reviewed the manuscript. All authors approved the final version of the manuscript and agree to be accountable for all aspects of the work in ensuring that questions related to the accuracy or integrity of any part of the work are appropriately investigated and resolved.
\end{abstract}

\section{Funding}

This work was supported in part by Grants-in-Aids for Scientific Research from JSPS Grant No. 19 K18720.

\section{Availability of data and materials}

The datasets analyzed during the current study are available from the corresponding author on reasonable request.

Ethics approval and consent to participate

This study was performed in accordance with the Helsinki Declaration and approved by the Institutional Review Board of Tohoku University Hospital (Number 2014-1-274)

\section{Consent for publication}

All patients provided written, informed consent for publication.

\section{Competing interests}

The authors declare that they have no competing interests.

Received: 28 February 2020 Accepted: 5 May 2020

Published online: 02 June 2020

\section{References}

1. Chen AY, Frankowski R, Bishop-Leone J, et al. The development and validation of a dysphagia-specific quality-of-life questionnaire for patients with head and neck cancer: the M. D. Anderson dysphagia inventory. Arch Otolaryngol Head Neck Surg. 2001;127(7):870-6.

2. Shune SE, Karnell LH, Karnell MP, Van Daele DJ, Funk GF. Association between severity of dysphagia and survival in patients with head and neck cancer. Head Neck. 2012;34(6):776-84.

3. Van der Molen L, van Rossum MA, Burkhead LM, Smeele LE, Hilgers FJ. Functional outcomes and rehabilitation strategies in patients treated with chemoradiotherapy for advanced head and neck cancer: a systematic review. Eur Arch Otorhinolaryngol. 2009;266(6):889-900.

4. Manikantan K, Khode S, Sayed SI, et al. Dysphagia in head and neck cancer. Cancer Treat Rev. 2009;35(8):724-32.

5. Jung SJ, Kim DY, Joo SY. Rick factors associated with aspiration in patients with head and neck cancer. Ann Rehabil Med. 2011;35(6):781-90.

6. Yamaya M, Yanai M, Ohrui T, Arai H, Sasaki H. Interventions to prevent pneumonia among older adults. J Am Geriatr Soc. 2001;49:85-90.

7. Tohara H, Saitoh E, Mays KA, Kuhlemeier K, Palmer JB. Three tests for predicting aspiration without Videofluorography. Dysphagia. 2003;18(2): 126-34.

8. Langmore SE, Schatz K, Olsen N. Fiberoptic endoscopic examination of swallowing safety: a new procedure. Dysphagia. 1988;2:216-9.

9. Ebihara $T$, Takahashi $H$, Ebihara $S$, et al. Capsaicin troche for swallowing dysfunction in older people. J Am Geriatr Soc. 2005;53:824-8. 
10. Eisbruch A, Lyden T, Bradford CR, et al. Objective assessment of swallowing dysfunction and aspiration after radiation concurrent with chemotherapy for head-and-neck cancer. Int J Radiat Oncol Biol Phys. 2002;53:23-8.

11. Stenson KM, MacCracken E, List M, et al. Swallowing function in patients with head and neck cancer prior to treatment. Arch Otolaryngol Head Neck Surg. 2000;126(3):371-7.

12. Pauloski BR, Rademaker AW, Logemann JA, et al. Pretreatment swallowing function in patients with head and neck cancer. Head Neck. 2000;22(5):474-82.

13. Hutcheson KA, Lewin JS. Functional outcomes after chemoradiotherapy of laryngeal and pharyngeal cancers. Curr Oncol Rep. 2012;14(2):158-65.

14. Patterson JM, McColl E, Carding PN, Hildreth AJ, Kelly C, Wilson JA. Swallowing in the first year after chemoradiotherapy for head and neck cancer: clinician- and patient-reported outcomes. Head Neck. 2014;36(3): 352-8.

15. Ohkoshi A, Ogawa T, Nakanome A, et al. Predictors of chewing and swallowing disorders after surgery for locally advanced oral cancer with free flap reconstruction: a prospective, observational study. Surg Oncol. 2018: 39(2): $77-81$.

16. Ebihara $\mathrm{T}$, Ebihara $\mathrm{S}$, Watando $\mathrm{A}$, et al. Effects of menthol on the triggering of the swallowing reflex in elderly patients with dysphagia. Br J Clin Pharmacol. 2006;62(3):369-71.

17. Nakzawa H, Sekizawa K, Ujiie Y, Sasaki H, Takishima T. Risk of aspiration pneumonia in the elderly. Chest. 1993;103:1636-7.

18. Langerman A, Maccracken E, Kasza K, Haraf DJ, Vokes EE, Stenson KM. Aspiration in chemoradiated patients with head and neck cancer. Arch Otolaryngol Head Neck Surg. 2007:133(12):1289-95.

19. Newman LA, Vieira F, Schwiezer V, et al. Eating and weight changes following chemoradiation therapy for advanced head and neck cancer. Arch Otolaryngol Head Neck Surg. 1998;124(5):589-92.

20. Hovan AJ, Williams PM, Stevenson-Moore P, et al. A systematic review of dysgeusia induced by cancer therapies. Support Care Cancer. 2010;18(8): 1081-7.

21. Logemann JA, Pauloski BR, Rademaker AW, et al. Xerostomia: 12-month changes in saliva production and its relationship to perception and performance of swallow function, oral intake, and diet after chemoradiation Head Neck. 2003;25(6):432-7.

22. Nguyen NP, Moltz CC, Frank C, Millar C, Smith HJ, Dutta S, et al. Effectiveness of the cough reflex in patients with aspiration following radiation for head and neck cancer. Lung. 2007:185(5):243-8.

23. Höckerfelt U, Franzén L, Norrgård O, Forsgren S. Early increase and later decrease in VIP and substance $P$ nerve fiber densities following abdominal radiotherapy: a study on the human colon. Int J Radiat Biol. 2002;78(11): 1045-53.

24. Ishii R, Kato K, Ogawa T, et al. Poor oral intake causes enteral nutrition dependency after concomitant chemoradiotherapy for pharyngeal cancers. Eur Arch Otorhinolaryngol. 2018;275(6):1607-11.

25. Fujiki M, Sakuraba M, Miyamoto S, Hayashi R. Predictive factors of dysphagia after lateral and superior oropharyngeal reconstruction with free flap transfer. Surg Oncol. 2016;113(2):240-3.

\section{Publisher's Note}

Springer Nature remains neutral with regard to jurisdictional claims in published maps and institutional affiliations.

Ready to submit your research? Choose BMC and benefit from:

- fast, convenient online submission

- thorough peer review by experienced researchers in your field

- rapid publication on acceptance

- support for research data, including large and complex data types

- gold Open Access which fosters wider collaboration and increased citations

- maximum visibility for your research: over $100 \mathrm{M}$ website views per year

At $\mathrm{BMC}$, research is always in progress.

Learn more biomedcentral.com/submissions 